\title{
A case of congenital aneurysm of the ulnar artery of the palm
}

Yoko Kishi

Department of Pediatric Surgery, Dokkyo Medical University Saitama Medical Center, Saitama 343-8555, Japan.

Correspondence to: Dr. Yoko Kishi, Department of Pediatric Surgery, Dokkyo Medical University Saitama Medical Center, 2-1-50

Minami-Koshigaya, Koshigaya, Saitama 343-8555, Japan. E-mail: kishi-y@dokkyomed.ac.jp

How to cite this article: Kishi Y. A case of congenital aneurysm of the ulnar artery of the palm. Plast Aesthet Res 2020;7:3.

http://dx.doi.org/10.20517/2347-9264.2019.50

Received: 3 Nov 2019 First Decision: 23 Dec 2019 Revised: 8 Jan 2020 Accepted: 14 Jan 2020 Published: 21 Jan 2020

Science Editor: A Thione Copy Editor: Jing-Wen Zhang Production Editor: Tian Zhang

\begin{abstract}
Congenital aneurysms of the palm are uncommon in the pediatric population compared to aneurysms in adults. A seven-month-old boy presented with a true aneurysm of the ulnar artery with reconstruction with surgical excision and end-to-end microvasculer anastomosis using a superficial vein of the dorsal foot. To our knowledge, there have been only 15 reports of congenital aneurysms of the palm.
\end{abstract}

Keywords: Congenital aneurysm of the palm, ulnar artery, microvascular reconstruction

\section{INTRODUCTION}

Hypothenar hammer syndrome is characterized by aneurysm in the palm; it is most commonly caused by trauma. Congenital aneurysm in the palm is relatively rare.

To our knowledge, there are only two reports ${ }^{[1,2]}$ on congenital aneurysm in the palm in the Japanese literature and 13 reports $^{[3-15]}$ in the English literature.

We describe a case of congenital aneurysm of the ulnar artery in the palm of a nine-month-old baby boy. We reviewed the literature on congenital aneurysm to identify the site of occurrence, affected side, treatment procedure, and outcomes. 

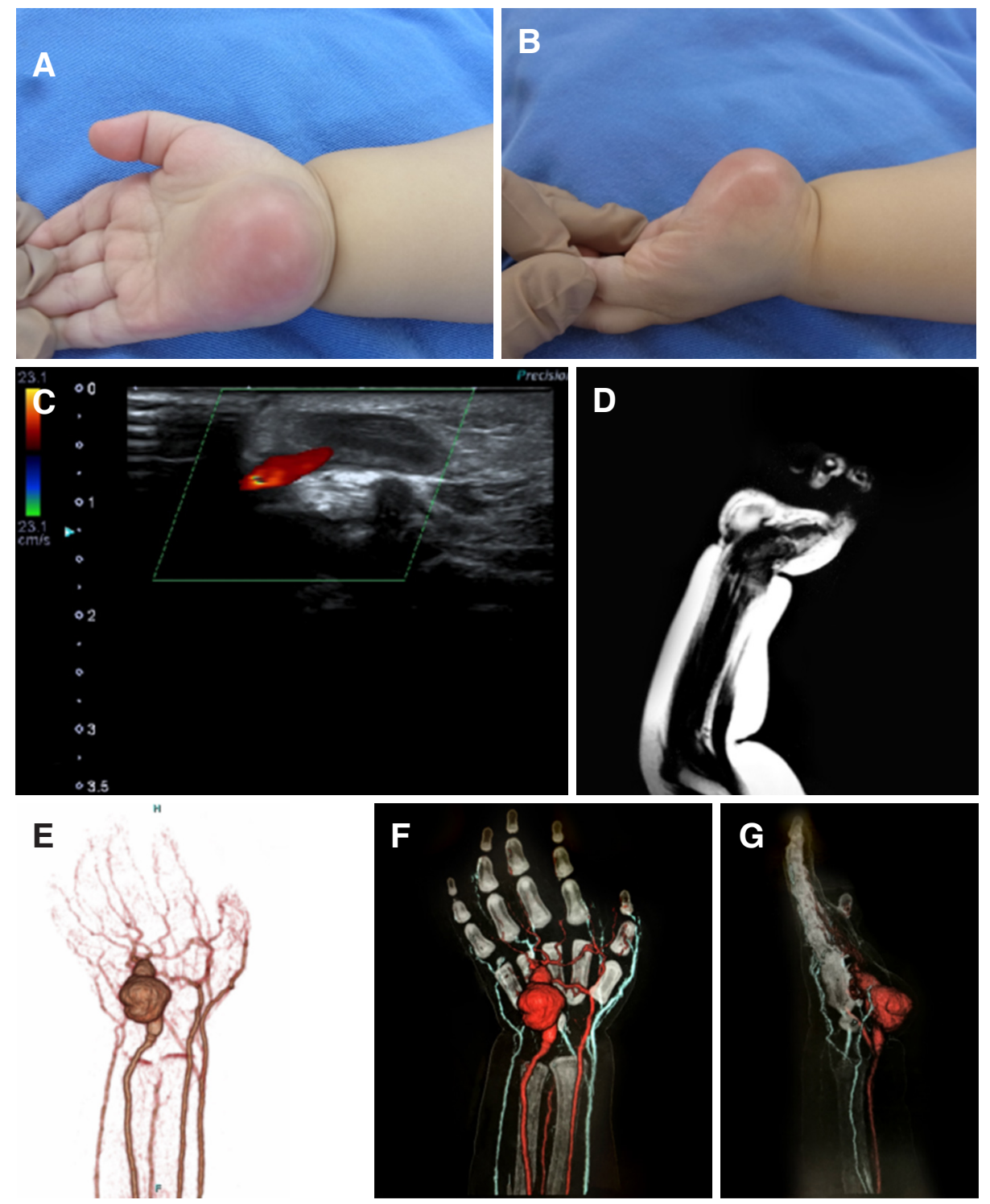

Figure 1. Patient presented with a large pulsatile palmar mass. A: Clinical findings; front view; B: lateral view; C: color doppler ultrasound imaging; D: MRI findings; E: MRA findings; F: 3D view (frontal); G: 3D view (lateral)

\section{CASE REPORT}

The family of a seven-month-old boy noticed a protuberance on the palm of his right hand. His parents took him to a dermatology clinic, from where he was referred to our hospital for treatment. On the first visit, the protuberance was diagnosed as a pulsatile subcutaneous tumor, measuring $25 \mathrm{~mm} \times 25 \mathrm{~mm}$ [Figure $1 \mathrm{~A}$ and $\mathrm{B}]$.

A Doppler ultrasound revealed marked expansion of the lumen of the ulnar artery distal to the wrist [Figure $1 \mathrm{C}]$.

T2-weighted magnetic resonance imaging (MRI) revealed uneven high signal intensity and T1-weighted MRI showed low signal intensity that was not fat-suppressed [Figure 1D].

Magnetic resonance angiography (MRA) revealed expansion of the artery extended between the palmar carpal branch of the ulnar artery and the superficial palmar arch [Figure 1E-G]. Surgery was scheduled for resection of the aneurysm and reconstruction of the artery using the superficial saphenous vein taken from 

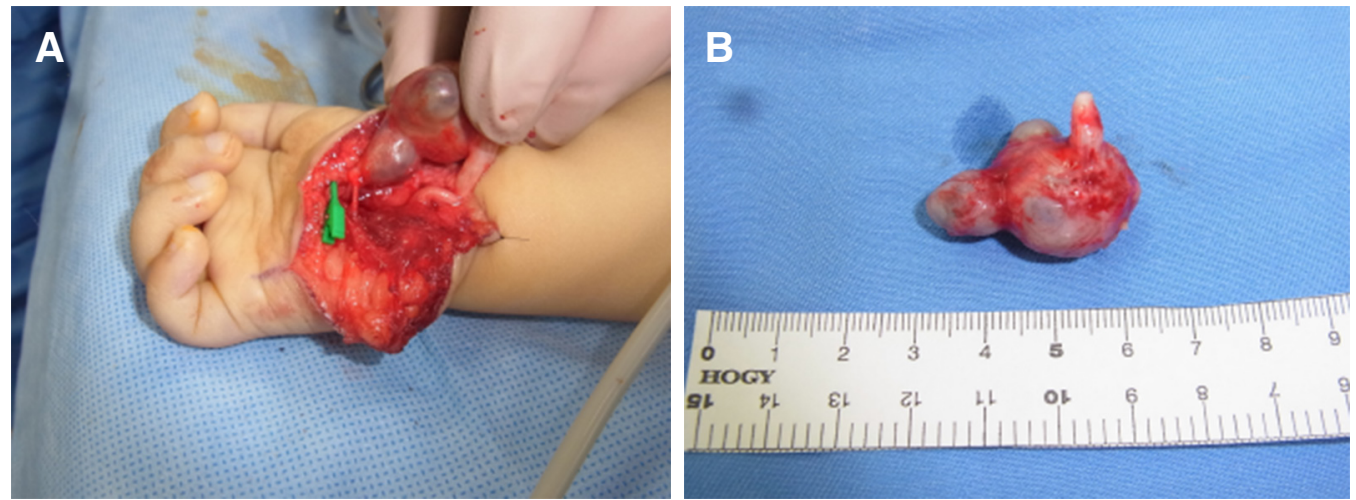

Figure 2. Intraoperative view A: the aneurysm was elevated; B: total view of the mass
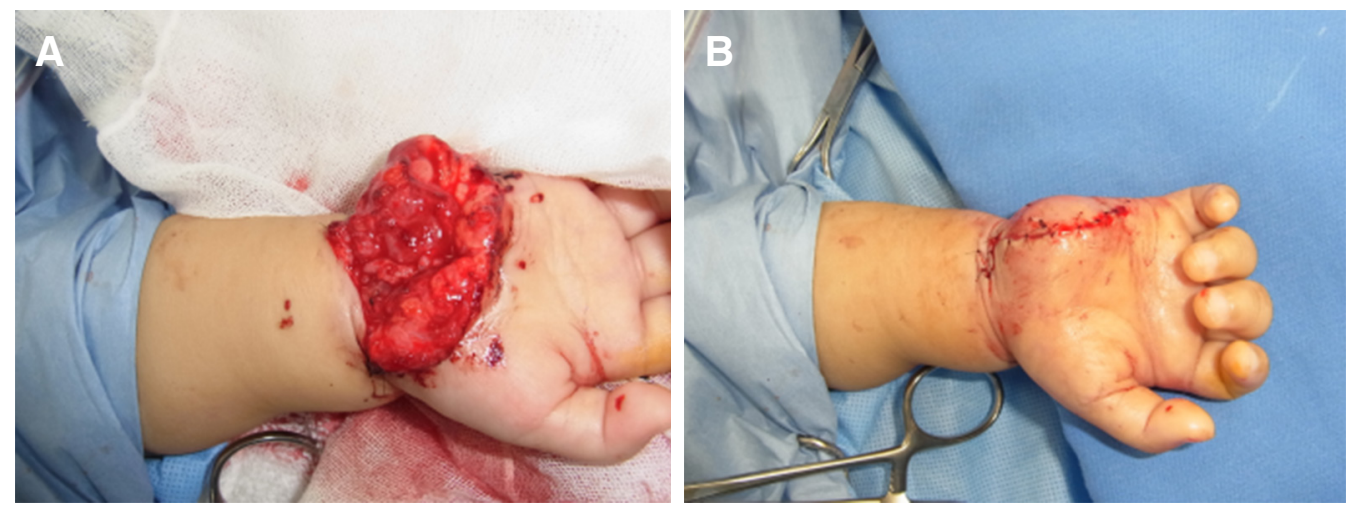

Figure 3. The recipient vein was anastomosis between the ulnar artery and superficial palmar arch

the dorsal foot at nine months of age. With the patient under anesthesia, a tourniquet was placed on the left upper arm and inflated to $200 \mathrm{mmHg}$. A lazy-S skin incision was drawn from the metacarpophalangeal joint of the little finger on the palmar side to the midpalm carpal line. The incision line was extended to transverse the wrist and elongated toward the forearm longitudinally. Next, the fat tissue layer was dissected to reach the lesion. The aneurysm was dissected from the ulnar artery at the wrist to the bifurcation of the proper palmar digital artery at the superficial palmar arch. Following the release of the cubital tunnel, the proximal part of the aneurysm was identified and a 30-g vessel clip was applied to both ends of the section that was judged to be the aneurysm expansion. The total size of the aneurysm was approximately $32 \mathrm{~mm} \times$ $25 \mathrm{~mm} \times 22 \mathrm{~mm}$ [Figure $2 \mathrm{~A}$ and $\mathrm{B}$ ].

The vain on the dorsal foot that was confirmed prior to the operation using AccuVein ${ }^{\mathrm{TX}}$ (Accu Vein LLC New York). About $2 \mathrm{~cm}$ of the vein was harvested as an interposition graft because the great saphenous vein is difficult to remove, although its diameter is good for anastomosis. The lumen of the vein was washed using a 1:20,000 solution of heparin in physiological saline. Under microscopic guidance, the aneurysm was resected, and the ulnar artery was anastomosed to the donor vein using 10-0 nylon suture. The clip was removed, and the pulsation was identified. The transverse palmar ligament, fat tissue, dermis, and epidermis were loosely sutured layer by layer [Figure $3 \mathrm{~A}$ and $\mathrm{B}$ ].

Bulky dressing was applied. To relieve shock on the palmar side, a cast with a Reston ${ }^{\text {TM }}$ (3M. St Paul. Minnesota) self-adhering foam padding was fixed on the palmar side. Pathological examination showed 

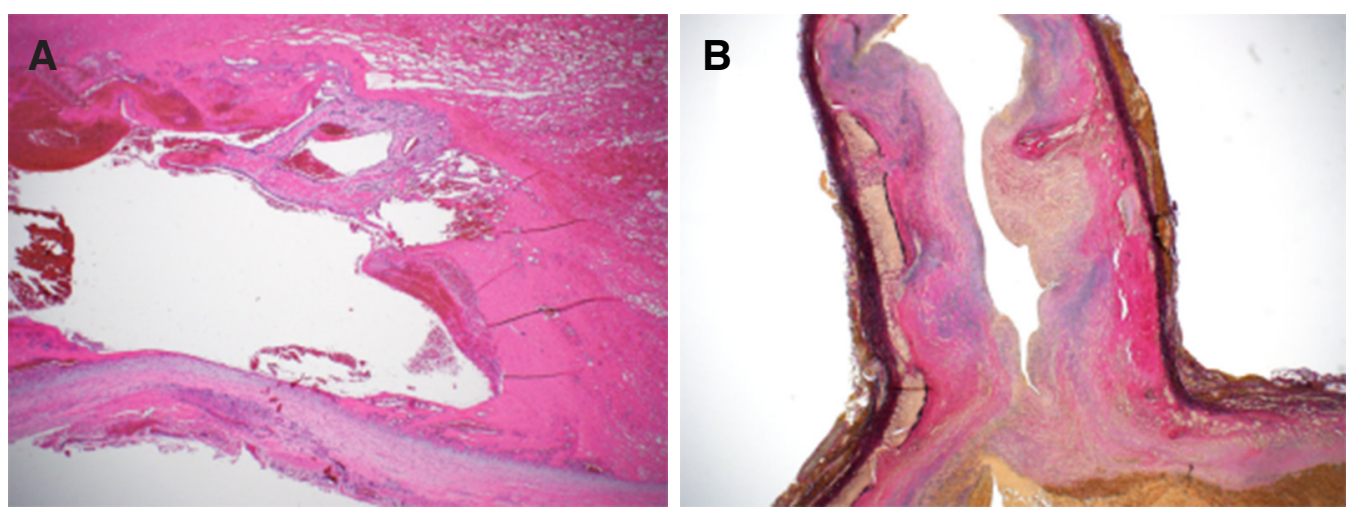

Figure 4. Pathological findings by Hematoxylin-Eosin stain $A$ : the hemorrhage was shown and the normal structure of the artery was broken $\times 20$; B: the neck of the aneurysm $\times 4$
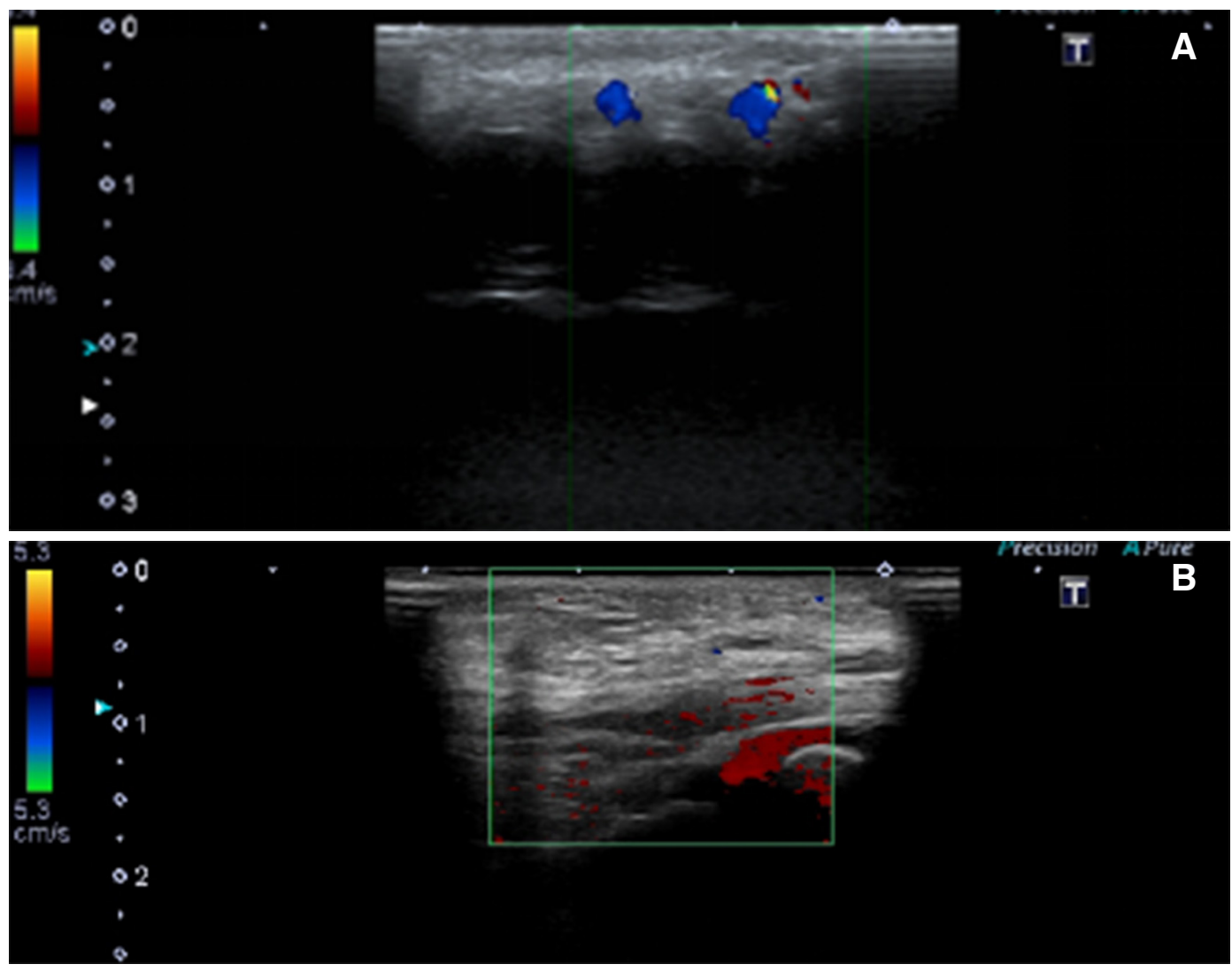

Figure 5. The left side is the ulnar artery and The longitudinal view of the the right side is the radial artery anastomotic graft vein (red). at the middle part of the palm (blue)

that the arterial wall was expanded with increased irregular fibrous tissue deposition. The normal architecture was distorted, and a thrombus had become a substrate [Figure $4 \mathrm{~A}$ and $\mathrm{B}$ ].

After surgery, heparin sodium and prostaglandin infusion were administered for one week to prevent thrombosis and spasm. At two weeks after surgery, prognosis was excellent, and the patient was discharged home safely. Every two weeks, he was checked for the condition of the anastomosed vessels by ultrasonography [Figure $5 \mathrm{~A}$ and $\mathrm{B}]$. 
Table 1. Patient characteristics of all reports of congenital true palmar aneurysms

\begin{tabular}{|c|c|c|c|c|c|c|c|c|}
\hline Ref. & $\begin{array}{c}\text { Published } \\
\text { year }\end{array}$ & Age & Sex & Side & Dominant & Artery & $\begin{array}{c}\text { Collagen } \\
\text { vascular } \\
\text { disease }\end{array}$ & Operation \\
\hline Okuda et al. ${ }^{[1]}$ & 1987 & 5 years & $\mathrm{F}$ & $\mathrm{R}$ & & Palmar arch 4 & & Resection \\
\hline Rikukawa et al.. ${ }^{[2]}$ & 1992 & 12 years & $M$ & $L$ & & Ulnar & & $\begin{array}{l}\text { Resection: end to end } \\
\text { anastomosis }\end{array}$ \\
\hline Martin et $a I^{[3]}$ & 1982 & 18 years & $M$ & $\mathrm{R}$ & Left & Ulnar & & $\begin{array}{l}\text { Resection + vein graft, } \\
\text { superficial v }\end{array}$ \\
\hline Itoh et al. ${ }^{[4]}$ & 1992 & 8 months & $M$ & $\mathrm{~L}$ & & $\begin{array}{l}\text { Common } \\
\text { digital }\end{array}$ & & Resection \\
\hline Offer et al..$^{[5]}$ & 1999 & 1 year & $M$ & $\mathrm{~L}$ & & Ulnar & & Resection \\
\hline Witt et $a{ }^{[6]}$ & 2003 & 8 years & M & $L$ & & Ulnar & & $\begin{array}{l}\text { Resection + vein graft, } \\
\text { reverse saphenous vein }\end{array}$ \\
\hline Deune et $a .^{[7]}$ & 2005 & 4 years & M & $\mathrm{L}$ & & Ulnar & + & Resection + vein graft \\
\hline Al-Omran et al. ${ }^{[8]}$ & 2007 & 18 months & $M$ & $L$ & & Ulnar & + Kawasaki & Resection \\
\hline Parsa et al..$^{[9]}$ & 2008 & 12 years & $M$ & $\mathrm{R}$ & Right & Ulnar & & Resection + vein graft \\
\hline Amjad et $a l^{[10]}$ & 2010 & 2 years & $M$ & $\mathrm{~L}$ & & Ulnar & & Resection \\
\hline Iyer et al.. ${ }^{[11]}$ & 2012 & 5 months & $\mathrm{F}$ & $L$ & & Ulnar & & Resection ligated \\
\hline Stalder et al.. ${ }^{[12]}$ & 2016 & 15 years & $M$ & $L$ & Right & Ulnar & & $\begin{array}{l}\text { Resection + vein graft, } \\
\text { cephalic vein }\end{array}$ \\
\hline Shutze et $a{ }^{[13]}$ & 2017 & 16 years & $\mathrm{F}$ & $\mathrm{L}$ & & $\begin{array}{l}\text { Common } \\
\text { digital }\end{array}$ & & Resection \\
\hline Meals et al. ${ }^{[14]}$ & 2017 & 6 months & M & $\mathrm{L}$ & & $\begin{array}{l}\text { Common } \\
\text { digital }\end{array}$ & & Resection \\
\hline Dean et $a{ }^{[15]}$ & 2019 & 13 months & $M$ & $\mathrm{R}$ & & $\begin{array}{l}\text { Common } \\
\text { digital }\end{array}$ & & Resection \\
\hline Our case & 2019 & 7 months & $M$ & $\mathrm{R}$ & & Ulnar & & Resection + vein graft \\
\hline
\end{tabular}

A palmar gypsum cast with Reston ${ }^{\mathrm{TM}}$ was kept in place for one year and his condition was satisfactory as of this writing. There were no complications or abnormalities of blood flow or the median or ulnar nerve.

\section{DISCUSSION}

In Japan, 12 reports have been published on aneurysms in the palm, of which 10 were caused by trauma, one had unknown etiology, and only one was diagnosed by Okuda et al. ${ }^{[1]}$ as a congenital aneurysm. In the English literature, we found only 14 reports on aneurysms in the palm ${ }^{[2,3,15]}$, five of which were diagnosed as congenital aneurysm but with underlying arteriosclerosis. Most aneurysms were caused by blunt trauma, especially those located in the palm, and were thought to have arisen because the ulnar artery was sandwiched between the hamate bone and skin. Such cases are considered to represent hypothenar hammer syndrome. In 1772, Guattani ${ }^{[16]}$ was the first to describe a palmar aneurysm with most of the 52 reported cases being caused by trauma and 30 involving the ulnar artery.

Doppler ultrasound can be used to detect the characteristic yin-yang sign of congenital aneurysm. MRI is also effective for examining the luminal of the artery. MRA is however the most effective method for examining vascular flow. According to the pathological findings, congenital aneurysms are characterized by a poor inflammation and no arteriosclerosis. It is easy to distinguish them from congenital arteriovenous fistula using arteriographic and MRA imaging findings. Furthermore, it is difficult to detect congenital aneurysms in one-year-old children because identification of its symptoms is challenging in this population, and the only physical finding is often a bump in the palm.

Among the 15 cases previously reported ${ }^{[1-15]}$, the site of occurrence was the ulnar artery in 10 cases, the common digital artery in four cases, and the palmar arch in one case; the ulnar artery was involved in $67 \%$ of cases [Table 1]. 
Eleven of the fifteen cases described were on the left side.

One of the cases in which the aneurysm occurred in the dominant hand was a right-sided aneurysm in a 12-year-old boy; one patient was very young, and investigators could not judge the dominant hand. Our case was not identified as occurring in the dominant side on the first visit; however, one year later, it appeared that the dominant side was the right side.

The age of onset ranged from 5 months to 16 years with a mean of six years, Treatment was carried out in all 15 cases. Simple excision was performed for eight cases and reconstruction for seven cases; one needed end-to-end anastomosis, five needed vein graft, and one needed a combination with sclerotherapy. Embolization was not selected because it may impair blood flow in the common digital arteries. We chose to use a vein graft from the saphenous vein because there was a $2-\mathrm{cm}$ diameter gap between the affected arteries; the aneurysm was located at the edge of the deep palmar arch; and the mobility of the ulnar artery was poor. If the distance between the defect of the artery had been short, we could have directly sutured the artery. The donor vein was difficult to anastomose because its diameter was one-third that of the ulnar artery. Furthermore, it was difficult to obtain a good vein to fit the diameter of the recipient artery from a nine-month-old boy with minimal injury because the fat layer at that region around the saphenous vein was thick and therefore the resulting wound was considerably longer. Two cases in the literature had a history of collagen disease, namely Kawasaki disease, Marfan's syndrome, Loeys-Dietz syndrome, osteogenesis imperfect, and Ehlers-Danlos syndrome. Our patient had no evidence of these diseases. We diagnosed this as a congenital aneurysm in the palm because it was a true aneurysm, with poor infiltration, no arterial sclerosis on pathological findings, and no evidence of collagen disease or trauma.

In conclusion, arterial aneurysms of the palm in the pediatric population are rare. Our case was a righthanded seven-month-old boy. The patient underwent operative exploration with arterial reconstruction to interpose between the defect using a dorsal pedal vein. The patient recovered well without any complication. Including the present case, there have been only 16 cases of congenital aneurysms in the palm.

\section{DECLARATIONS}

\section{Authors' contributions}

The author contributed solely to the article.

Availability of data and materials

Not applicable.

Financial support and sponsorship

None.

\section{Conflicts of interest}

The author declared that there are no conflicts of interest.

\section{Ethical approval and consent to participate}

This study was condacted in accordance with the declaration of Helsinki.

\section{Consent for publication}

A written informed consent was obtained from all patients. 


\section{Copyright}

(c) The Author(s) 2020.

\section{REFERENCES}

1. Okuda H, Koshikawa A, Kawada Y, Kurata A. Congenital aneurysm in the palm:a case report. Orthop Surg 1987.

2. Rikukawa H, Kudo T, Takahashi K.at.al.A case report of true palmar aneurysm. J. Japan Surgical Society 1992;93:445-7.

3. Martin RD, Manktelow RT. Management of ulnar artery aneurysm in the hand: a case report. Can J Surg 1982;25:97-9.

4. Itoh M, Takato T, yokota M. Upper extremeity aneurysm in infants. Ann Plast Surg 1992;29:157-60.

5. Offer GJ, Sully L. Congenital aneurysm of the ulnar artery in the palm. J Hand Surg Br 1999;24:735-7.

6. Witt PD, Bowen KA, Johansen K. True ulnar artery aneurysm of the hand in an 8-year-old boy. Plast Reconstr Surg 2003;111:2475-6.

7. Deune EG, McCarthy EF. Reconstruction of a true ulnar artery aneurysm in a 4-year-old patient with radial artery agenesiss. Orthopedics 2005;28:1459-61.

8. Al-Omran M. True ulnar artery aneurysm of the hand in an 18-month-oldboy:a case report. J Vasc Surg 2007;45:841-3.

9. Parsa AA, Higashigawa K, Parsa FD. Arterial aneurysm of the hand. Hawaii Med J 2008;67:37-40.

10. Amjad I, Murphy T, Zahn E. Diagnosis and exciseon of an ulnar artery aneurysm in a two-year-old boy. Can J Plast Surg 2010;18:e15-6.

11. Iyer RS, Hanel DP, Enriquez BK, Weinberger E. Ulnar artery aneurysm causing palmar mass in 5-month-old girl. Pediatr Radiol 2012;42:1401-4

12. Stalder MW, Sanders C, Lago M, Hilaire HS. Multilocation tru ulnar artery aneurysm in a pediatric patient. Plast Reconstr Surg Glob Open 2016;4;e595.

13. Shutze RA, Leichty J, Shutze WP. Palmar aryery aneurysm. Proc (Bayl Univ Med Cent) 2017;30:50-1.

14. Meals CG, Carey GB, Higgins JP, Chang B. Ulnar artery aneurysm in a 6-month-old: a case report. Hand ( N Y) 2017;12:118-20.

15. Dean RA, Fleming SI, Zvavanjanja RC, Marques ES, Greives MR. Congenital aneurysm of the palmar digital artery: a case report and literature review. Radiol Case Rep 2019;14:83-7.

16. Guattani C. De externis aneurysmatibus manu chirurgica methodice pertractandis. Rome; 1772. 